\title{
Correction to: Validity Evidence of the Vanity Scale: Adaptation to Brazil and Relations with Personality
}

\author{
Jean Carlos Natividade ${ }^{1,2}$ - Nathalia Melo de Carvalho ${ }^{1}$. \\ Amanda Londero-Santos ${ }^{3}$. Lorena Maria Laskoski ${ }^{4}$
}

Published online: 14 December 2020

(C) Associação Brasileira de Psicologia 2020

\section{Correction to: Trends in Psychol https://doi.org/10.1007/s43076-020-00048-w}

This article was originally published with its main title in Portuguese, so it was updated with the main title in English. The original article has been corrected.

The online version of the original article can be found at https://doi.org/10.1007/s43076-020-00048-w

Jean Carlos Natividade jeannatividade@gmail.com

1 Department of Psychology, Pontifical Catholic University of Rio de Janeiro (PUC-Rio), Rio de Janeiro, Brazil

2 Laboratório de Pesquisa em Psicologia Social, Department of Psychology, PUC-Rio, Rua Marquês de São Vicente, 225, Rio de Janeiro, RJ 22451-900, Brazil

3 Department of Psychology, Federal University of Rio de Janeiro (UFRJ), Rio de Janeiro, Brazil

4 Department of Pediatrics, Federal University of Paraná (UFPR), Curitiba, Brazil 